\title{
Inhibition of long non-coding RNA-AWPPH decreases osteosarcoma cell proliferation, migration and invasion
}

\author{
WENBIN DING* ${ }^{*}$, DAJIANG WU* ${ }^{*}$ FANG JI and HAO ZHANG \\ Department of Traumatic Orthopedics, Changhai Hospital, Shanghai 200433, P.R. China
}

Received May 2, 2018; Accepted March 26, 2019

DOI: $10.3892 /$ ol.2019.10898

\begin{abstract}
Long non-coding RNAs (lncRNAs) serve a crucial role in various types of cancer. The lncRNA AWPPH has been reported to promote hepatocellular carcinoma and bladder cancer progression. However, to the best of our knowledge, the biological roles of AWPPH in osteosarcoma (OS) remain unclear. In the present study, the levels of AWPPH in OS tissues and cell lines were determined by reverse transcription-quantitative polymerase chain reaction. An MTT assay was used to detect OS cell proliferation. The levels of proteins associated with the PI3K/Akt signaling pathway and apoptosis were determined by western blotting. Wound-healing and Transwell assays were conducted to determine cell migration and invasion, respectively. The results demonstrated that AWPPH was highly expressed in OS tissues and cells. Functional analyses revealed that AWPPH depletion significantly inhibited OS cell proliferation and migration, and promoted OS cell apoptosis. Furthermore, AWPPH downregulation significantly inhibited the PI3K/AKT pathway. The present study demonstrated that AWPPH was highly expressed in OS, and that AWPPH promoted OS cell proliferation and migration, and inhibited OS cell apoptosis, which may be mediated by PI3K/AKT pathway activation.
\end{abstract}

\section{Introduction}

Osteosarcoma (OS) is a bone malignancy that primarily affects adolescents and young adults. OS accounts for $\sim 20 \%$ of all primary bone cancer cases in Europe and is the second highest cause of cancer-associated mortality in children (1). Despite advances in medical treatments, including

Correspondence to: Dr Hao Zhang or Dr Fang Ji, Department of Traumatic Orthopedics, Changhai Hospital, 168 Changhai Road, Shanghai 200433, P.R. China

E-mail: zhanghaodoct@163.com

E-mail: doctjf@163.com

${ }^{*}$ Contributed equally

Key words: osteosarcoma, long non-coding RNA-AWPPH, proliferation, migration, apoptosis surgery, transplantation and radiation, effective treatments for postsurgical recurrence and metastasis are not currently available, thus accounting for the poor patient outcome for OS (2). Although therapy for OS has improved, the overall survival rate of patients with OS has not substantially increased, and $35 \%$ of patients with OS die within 5 years of diagnosis (3). Furthermore, $>20 \%$ of young patients with OS present with distant metastases at the time of diagnosis, and $40 \%$ of advanced stage cases progress to metastasis during therapy $(4,5)$. To the best of our knowledge, the underlying molecular mechanism of metastasis in patients with OS has not yet been elucidated $(6,7)$. It is therefore crucial to identify novel biomarkers and therapeutic strategies for the better management of OS.

Long non-coding RNAs (lncRNAs) are polyadenylated RNA polymerase II-transcribed RNAs that are $\geq 200$ nucleotides in length and do not present obvious open reading frames to encode proteins (8-10). An increasing number of studies have demonstrated that lncRNAs serve crucial roles in tumor initiation, progression, metastasis, drug-resistance and recurrence (11-13). A previous study reported that epigenetic activation of the lncRNA-maternally expressed gene 3 (MEG3) and/or inactivation of the mesenchymal-epithelial transition factor could represent a therapeutic strategy in pancreatic neuroendocrine tumor and insulinoma treatment (14). IncRNAs affect a variety of biological processes, including cellular proliferation, differentiation, migration, the immune response and apoptosis, which are all associated with tumorigenesis $(15,16)$. However, the functional roles of lncRNAs remain commonly unknown. IncRNAs have been found to act as tumor suppressors or oncogenes (17-19). It has been reported that Ewing sarcoma-associated transcript 1 (EWSAT1) facilitates the growth and metastasis of OS cells via MEG3 regulation, which suggests that the EWSAT1-MEG3 axis may represent a promising target for OS treatment $(20,21)$. A meta-analysis indicated that MEG3 may be considered as a potential novel biomarker for the clinical outcome of certain types of human cancer (22), including bladder cancer (23), cervical carcinoma (24), hepatocellular cancers (25) and meningiomas (26). AWPPH is a novel IncRNA that has been reported to be involved in the development of several types of cancer and to have oncogenic functions $(27,28)$. For examples, a recent study reported that AWPPH is overexpressed in hepatoma cells, where it can promote proliferation and migration of liver cancer cells, and stimulate the growth and metastasis 
of tumor cells by interacting with Y-box binding protein 1 (YBX1) (29). However, it remains unclear whether AWPPH could be considered as a critical regulator in OS that could predict patient prognosis.

The present study aimed to evaluate the effects of AWPPH on OS cell proliferation, migration and apoptosis. Furthermore, this study will investigate the role of AWPPH on the regulation of phosphorylated (p)-PI3K, p-AKT, Bcl-2 and cleaved-caspase-3 expressions, in order to determine the underlying mechanisms of AWPPH in OS.

\section{Materials and methods}

Patients. A total of 30 pairs of OS tissues and paracancerous tissues were obtained from 30 patients ( 17 men and 13 women) undergoing tumor resection at the Changhai Hospital (Shanghai, China) between April 2010 and October 2017. The average age of the patients was 22.34 years (age range, 10-59 years). All tissues (4-8 cm thickness) were immediately snap-frozen in liquid nitrogen and stored at $-80^{\circ} \mathrm{C}$ until further use. Written informed consent was obtained from all patients and the study protocol was approved by the Ethics Committee of the Changhai Hospital.

Cells and reagents. The OS MG-63 and U2OS, and the osteoblast hFOB1.19 cell lines were purchased from the American Type Culture Collection (ATCC). Fetal bovine serum (FBS), Dulbecco's modified Eagle's medium (DMEM) and the MTT assay were purchased from Sigma-Aldrich; Merck KGaA. Penicillin, streptomycin, glutamine and TRIzol ${ }^{\circledR}$ were obtained from Invitrogen; Thermo Fisher Scientific, Inc. Antibodies against p-PI3K (cat. no. 4228S), PI3K (cat. no. 4249S), p-Akt (cat. no. 4060S), Akt (cat. no. 9272S), Bcl-2 (cat. no. 15071S), Bax (cat. no. 2774) cleaved-caspase-3 (cat. no. 9661S), caspase-3 (cat. no. 9662), cleaved-caspase-9 (cat.no. 20750) and caspase-9 (cat. no. 9508) were obtained from Cell Signaling Technology, Inc. and used at 1:500 dilution according to the manufacturer's instructions. Antibody against GAPDH, (cat. no. sc-32233); mouse anti-rabbit IgG-HRP antibody, (cat. no. sc-2357) and

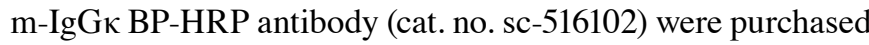
from Santa Cruz Biotechnology, Inc. and used at 1:5,000 dilution.

Cell culture. The MG-63 and U2OS cell lines were cultured in DMEM supplemented with $10 \% \mathrm{FBS}, 100 \mathrm{U} / \mathrm{ml}$ penicillin, $100 \mathrm{mg} / \mathrm{ml}$ streptomycin and $2 \mathrm{mM}$ glutamine, and placed at $37^{\circ} \mathrm{C}$ in a humidified incubator containing $5 \% \mathrm{CO}_{2}$.

ThehFOB1.19cell linewasculturedas previouslydescribed(30) and according to ATCC procedures. For in vitro proliferation, the hFOB1.19 cells were maintained in a non-differentiation medium that consisted of 1:1 DMEM/F-12 (GE Healthcare Life Sciences) containing 10\% FBS (Sigma-Aldrich; Merck KGaA) and $0.3 \mathrm{mg} / \mathrm{l} \mathrm{G} 418$ (Sigma-Aldrich; Merck KGaA), and cultured in a humidified incubator with $5 \% \mathrm{CO}_{2}$ at $34^{\circ} \mathrm{C}$. The medium was replaced every 2-3 days.

Short hairpin (sh)RNA transfection. The AWPPH shRNA used in the MG-63 and U2OS cell lines was purchased from Guangzhou RiboBio Co., Ltd. Cells were transfected using Lipofectamine ${ }^{\circledR} 3000$ (Invitrogen; Thermo Fisher Scientific,
Inc.) according to the manufacturer's instructions. The sequence of the AWPPH shRNA was 5'-CTGGATGGTCGC TGCTTTTTA-3'. AWPPH shRNA (100 nM) was inserted into the shRNA expression vector pGPH1/Neo (40 nM; Clontech Laboratories, Inc.) and packaged using Platinum-A (Cell Biolabs, Inc.). Cells $\left(1.2 \times 10^{6}\right)$ were transfected with AWPPH shRNA or scrambled shControl (5'-UUUCCGAACGUGUCA CGUdTdT-3') for $48 \mathrm{~h}$ prior to further experimentation.

MTT assay. The effect of AWPPH downregulation on MG63 and U2OS cell proliferation was measured by MTT assay. Cells $\left(1 \times 10^{4} / 100 \mu \mathrm{l}\right)$ were seeded in 96 -well plates. MTT $(50 \mu \mathrm{l})$ was added and the cells were incubated for $4 \mathrm{~h}$. Subsequently, $150 \mu \mathrm{l}$ DMSO was added to dissolve the purple formazan, and the absorbance was read at $570 \mathrm{~nm}$ with a microplate reader (Thermo Fisher Scientific, Inc.).

$R N A$ isolation and reverse transcription-quantitative polymerase chain reaction (RT- $q P C R)$. Total RNA from OS tissues, the two OS cell lines MG-63 and U2OS and the human osteoblast hFOB 1.19 cell line was isolated with TRIzol ${ }^{\circledR}$ according to the manufacturer's instructions. Total RNA concentration was determined with photometric method using a NanoQuant plate (Tecan Group, Ltd.). RNA (1 ng) was reverse transcribed using the Reverse EasyScript One-Step gDNA Removal and cDNA Synthesis SuperMix (Trangene) according to the manufacturer's instructions. RT-qPCR was performed using SYBR-Green Master mix (Roche Life Science) in an ABI 7500 Real-time PCR instrument according to the following reactions: Denaturation for 1 cycle at $95^{\circ} \mathrm{C}$ for $1 \mathrm{~min}$, followed by 40 cycles of $20 \mathrm{sec}$ at $95^{\circ} \mathrm{C}$ and $40 \mathrm{sec}$ at $58^{\circ} \mathrm{C}$. GAPDH was used as an endogenous control. The primers used were designed as follows: AWPPH forward, 5'-CTGGATGGTCGC TGCTTTTTA-3' and reverse, 5'-AGGGGGATGAGTCGT GATTT-3'; and GAPDH forward, 5'-GGAGCGAGATCC CTCCAAAAT-3' and reverse, 5'-GGCTGTTGTCATACT TCTCATGG-3'. The relative expression levels were normalized to endogenous controls and assessed using the $2^{-\Delta \Delta \mathrm{Cq}}$ method (31).

Cell migration and invasion assays. For the migration assay, 1x10 $10^{5}$ MG-63 and U2OS cells were seeded in six-well plates and cultured at $37^{\circ} \mathrm{C}$ overnight. A linear wound was carefully made with fine pipette-tips in the middle of the well, cell debris was removed and the cells were incubated with serum-free medium. The wounded monolayers were photographed at 0 and $24 \mathrm{~h}$ after wounding using an inverted microscope (magnification, 40x; Carl Zeiss AG).

For the invasion assay, $3 \times 10^{5} \mathrm{MG}-63$ and U2OS cells were seeded in FBS-free DMEM in the upper chamber of a 24-well Matrigel-coated Transwell invasion insert (diameter, $6.4 \mathrm{~mm}$; pore size, $8 \mu \mathrm{m}$; BD Biosciences). The lower chamber was filled with DMEM supplemented with $20 \%$ FBS. Following $24 \mathrm{~h}$ of incubation, the cells in the upper chamber were removed, and the cells that had invaded the membrane were stained using crystal violet for $20 \mathrm{~min}$ at room temperature. Five randomly selected fields were captured with an upright optical microscope (magnification, x10; Leica Microsystems $\mathrm{GmbH}$ ) and the migrated cells were counted. All experiments were performed in triplicate at least three times. 


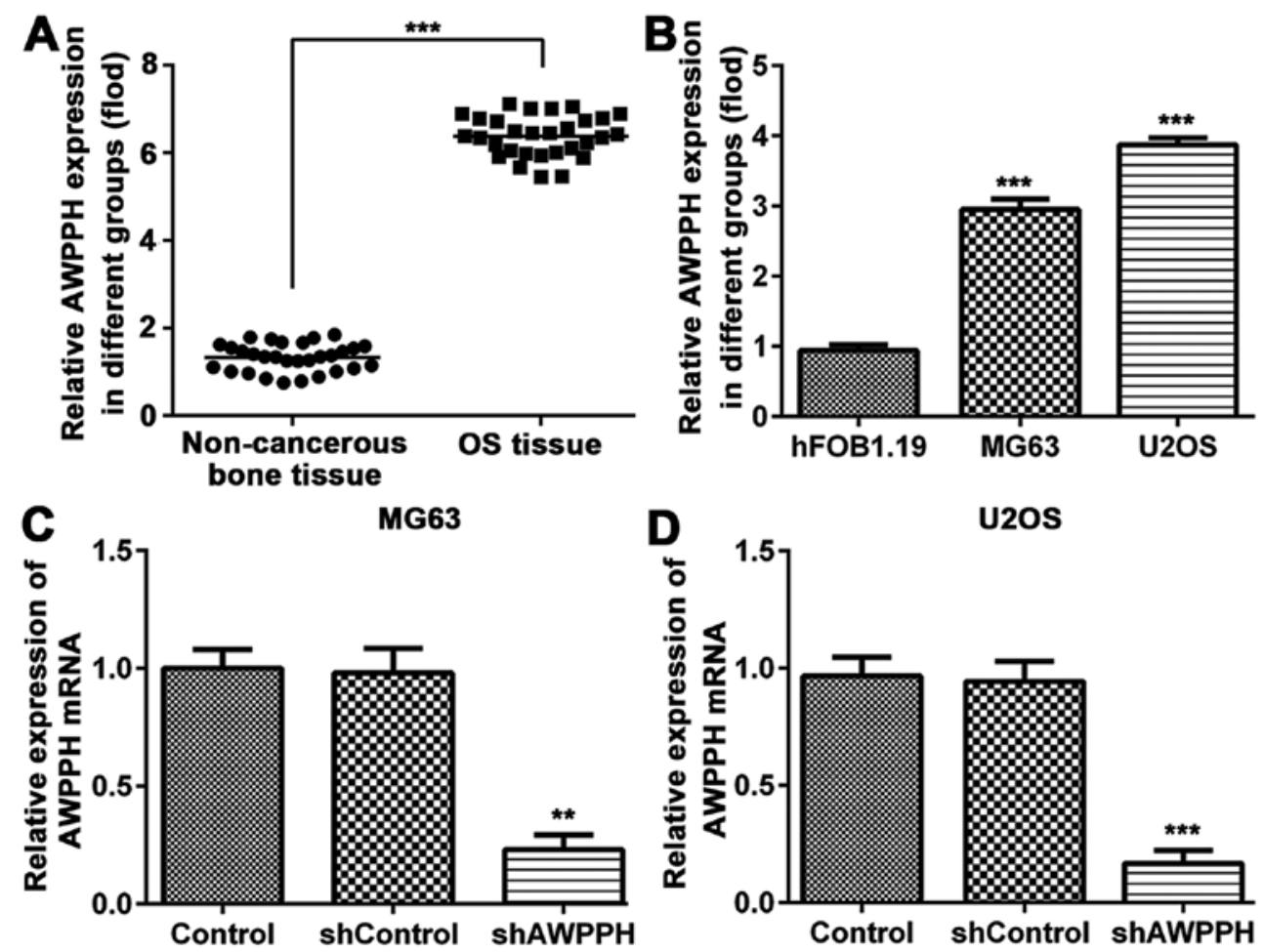

Figure 1. AWPPH is highly expressed in OS tissue and cells. The mRNA expression of AWPPH in (A) OS tissue and (B) MG-63, U2OS and hFOB1.19 cells was measured by RT-qPCR. (C) MG-63 and (D) U2OS cells were transfected with AWPPH shRNA and blank vector, and mRNA expression of lncRNA AWPPH was measured by RT-PCR. Data are expressed as the mean \pm standard error of the mean of 3 independent experiments in triplicate. ${ }^{* * *} \mathrm{P}<0.001$, compared to the para-matched bone tissues. ${ }^{* * *} \mathrm{P}<0.001$, compared to the hFOB1.19 cell, ${ }^{* * *} \mathrm{P}<0.01,{ }^{* * * *} \mathrm{P}<0.001$, compared to the control group. Non-cancerous bone tissue, para-matched bone tissues; Sh, short hairpin; RT-qPCR, reverse transcription-quantitative polymerase chain reaction.

Western blotting. MG-63 and U2OS cells were collected, and the total protein was extracted using RIPA lysis buffer (cat. no. P0013K; Beyotime Institute of Biotechnology) containing $1 \mathrm{mmol} / 1$ phenylmethylsulfonyl fluoride protease inhibitor (cat. no. ST506; Beyotime Institute of Biotechnology). Protein concentration of cell lysates was determined using a Bradford Protein Assay Kit (MultiSciences Biotech Co., Ltd.). Proteins $(40 \mu \mathrm{g})$ were separated by $12 \%$ SDS-PAGE and transferred to polyvinylidene difluoride membranes. Membranes were incubated with antibodies against p-PI3K, PI3K, p-Akt, Akt, Bcl-2, Bax, cleaved-caspase-3, caspase-3, cleaved-caspase-9, caspase- 9 and GAPDH at $4^{\circ} \mathrm{C}$ overnight. Membranes were washed with PBST and incubated with secondary antibodies for $1 \mathrm{~h}$ at room temperature. Enhanced chemiluminescence reagent (Thermo Fisher Scientific Inc.) was used to detect the signal on the membrane. Relative expression level of proteins was normalized to endogenous control GAPDH using Image-Pro Plus 6.0 (Media Cybernetics Inc.).

Statistical analysis. P-values were calculated using Student's t-test or one-way analysis of variance with SPSS software version 19.0 (IBM Corp.). All data are expressed as the mean \pm standard error of the mean. $\mathrm{P}<0.05$ was considered to indicate a statistically significant difference.

\section{Results}

AWPPH is highly expressed in OS tissues and cells. The expression levels of AWPPH in OS tissues, in the two OS cell lines MG-63 and U2OS, and in the human osteoblast
hFOB 1.19 cell line were detected by RT-qPCR. As presented in Fig. 1A, AWPPH expression levels were significantly elevated in OS tissues compared with those in non-cancerous matched bone tissues. In addition, the expression levels of AWPPH were significantly increased in the MG-63 and U2OS cell lines (Fig. 1B) compared with those in hFOB1.19 cells. In order to investigate the biological roles of AWPPH in OS cells, the MG-63 and U2OS cell lines were stably depleted of AWPPH using AWPPH-specific shRNA. RT-qPCR analysis reported that transfection with AWPPH shRNA effectively decreased AWPPH mRNA expression in the MG-63 and U2OS cells, compared with that in the control and shControl groups (Fig. 1C and D).

AWPPH downregulation inhibits OS cell proliferation, migration and invasion. As presented in Fig. 2A and B, MG63 and U2OS cell proliferation was significantly decreased following 48 and $72 \mathrm{~h}$ of transfection with AWPPH shRNA, compared with the negative control. The wound-healing assay demonstrated that AWPPH depletion decreased the migration capacity of the MG-63 (Fig. 2C) and U2OS (Fig. 2D) cells. In addition, the Transwell assay revealed that AWPPH depletion significantly inhibited MG-63 and U2OS cell invasion (Fig. 2E). These data suggested that AWPPH may serve a crucial role in OS cell proliferation, migration and invasion.

AWPPH downregulation promotes OS cell apoptosis-associated factors. In order to investigate whether cell apoptosis contributes to the decrease in cell viability, western blotting 
A
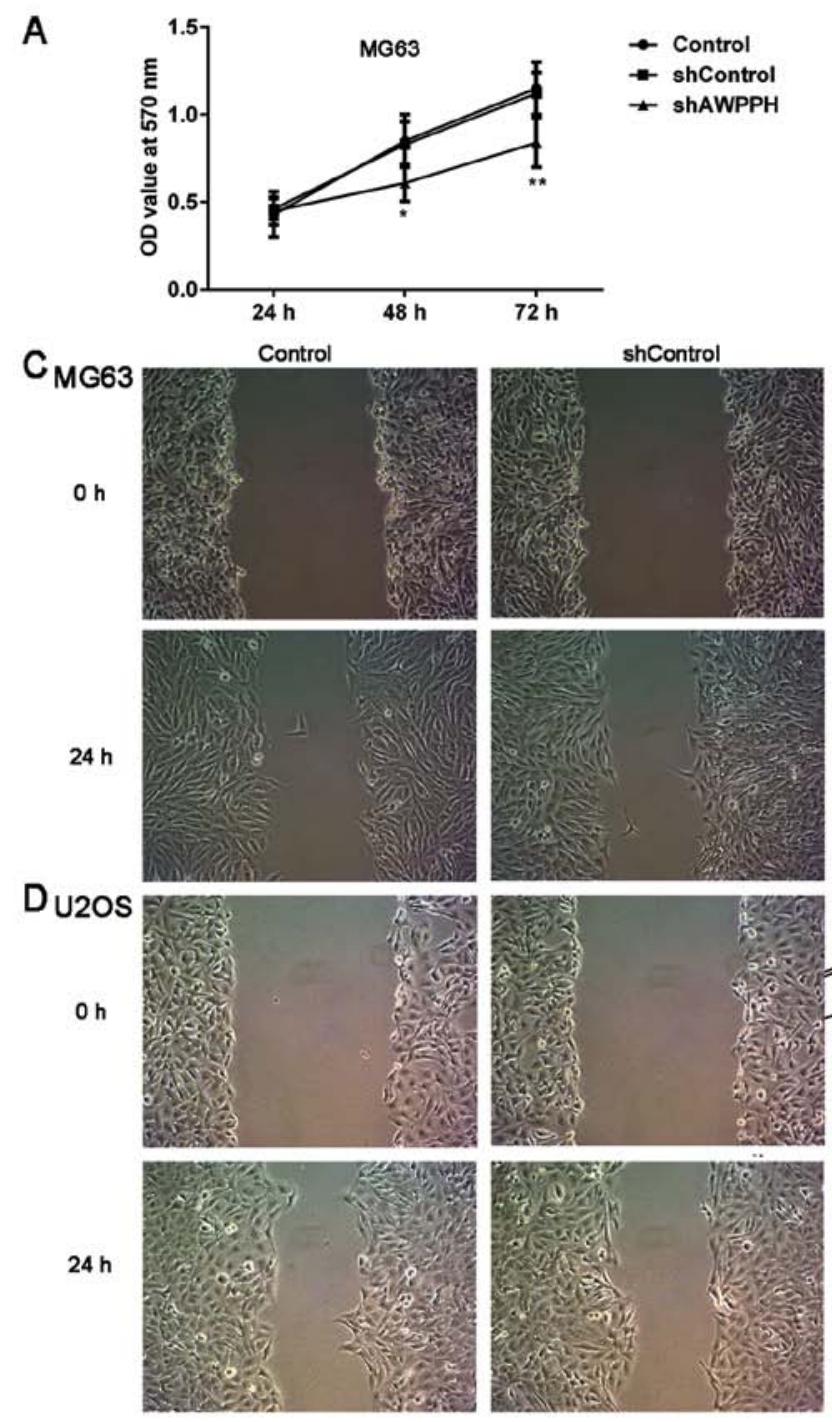

E
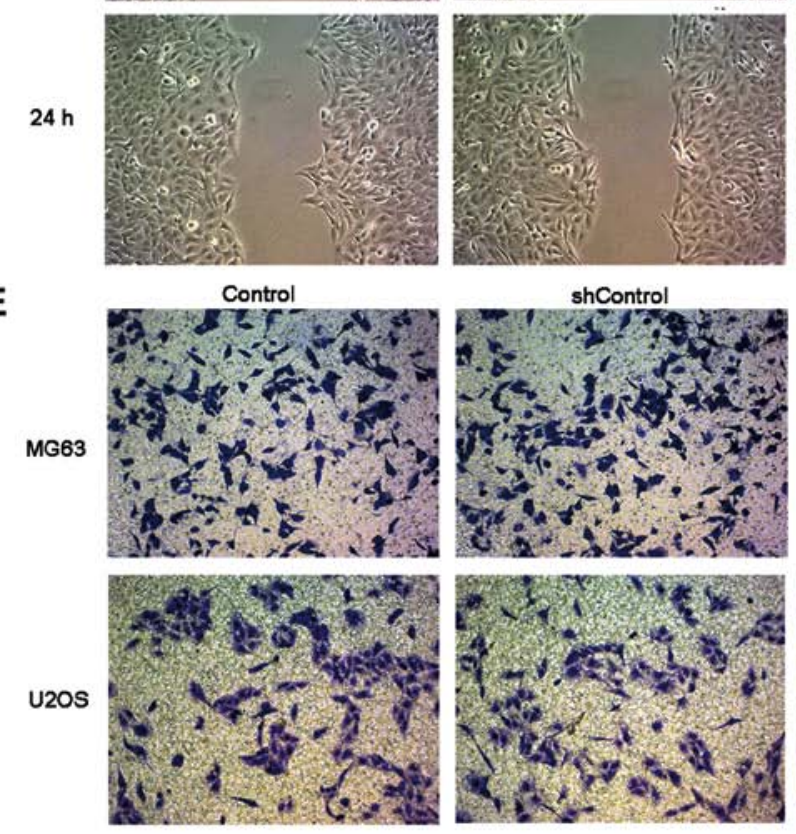
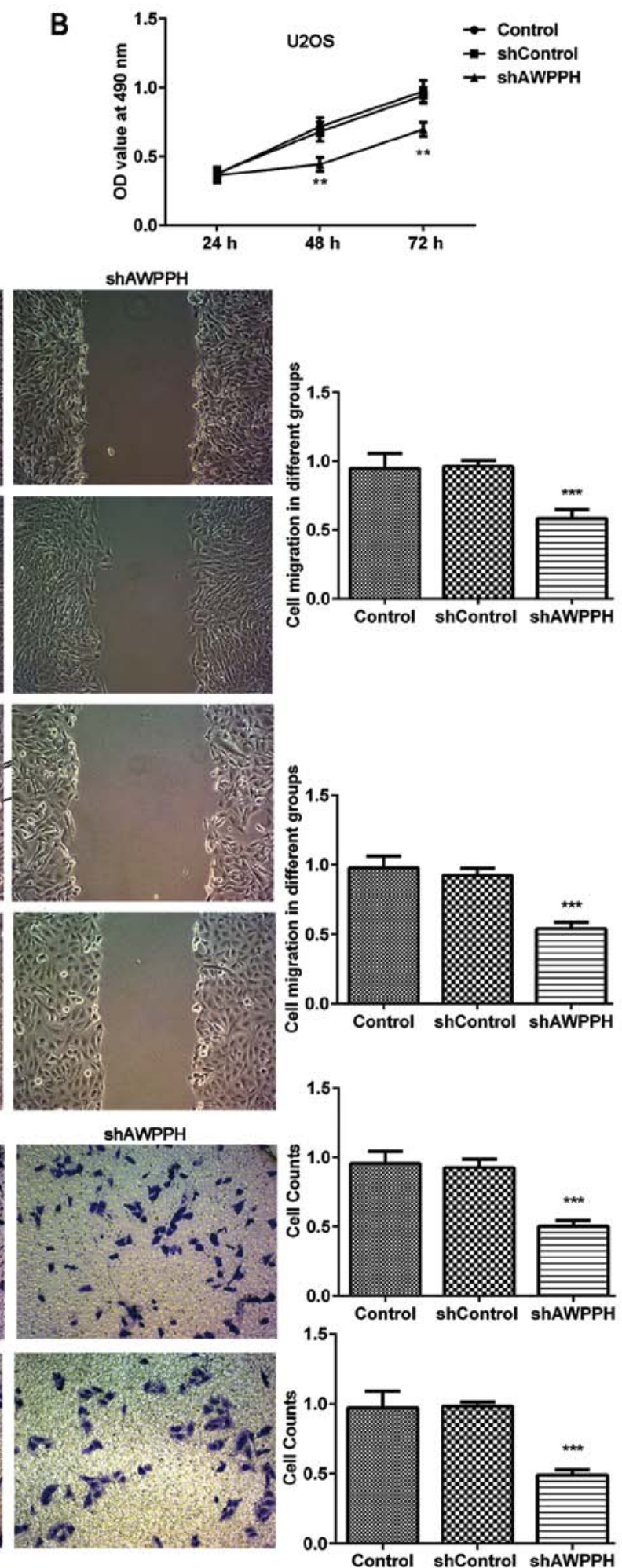

Figure 2. AWPPH downregulation inhibits OS cell proliferation, migration and invasion. (A) MG-63 and (B) U2OS cells were transfected with AWPPH shRNA and blank vector, and cell proliferation was measured by MTT at 24,48 and $72 \mathrm{~h}$ post-transfection. (C and D) Wound-healing and (E) Transwell assays were used to examine the cell migration and invasion of MG-63 and U2OS cells transfected with AWPPH shRNA. Data are expressed as the mean \pm standard error of the mean of three independent experiments in triplicate. $\mathrm{P}<0.05,{ }^{* *} \mathrm{P}<0.01$ and ${ }^{* * * *} \mathrm{P}<0.001$ compared with the control group. Sh, short hairpin; OD, optical density.

was used to detect cell apoptosis-associated proteins. The results demonstrated that cleaved-caspase-3, cleaved-caspase-9 and Bax expressions were significantly increased, whereas Bcl-2 expression was significantly decreased in the MG-63 and U2OS cells following transfection with AWPPH shRNA (Fig. 3A and B).
AWPPH downregulation inhibits the PI3K/AKT pathway. As presented in Fig. 4A and B, western blotting demonstrated that AWPPH depletion significantly decreased the protein levels of p-PI3K and p-AKT in the MG-63 and U2OS cells. These results suggested that AWPPH may partly function by activating the PI3K/AKT pathway. 
A ${ }_{\text {MG63 }}$

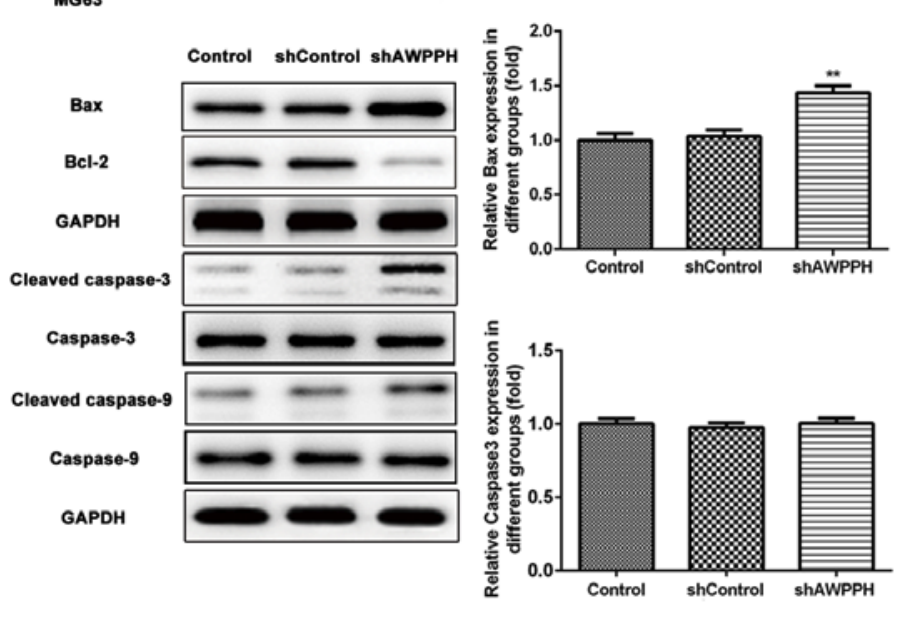

B u20s

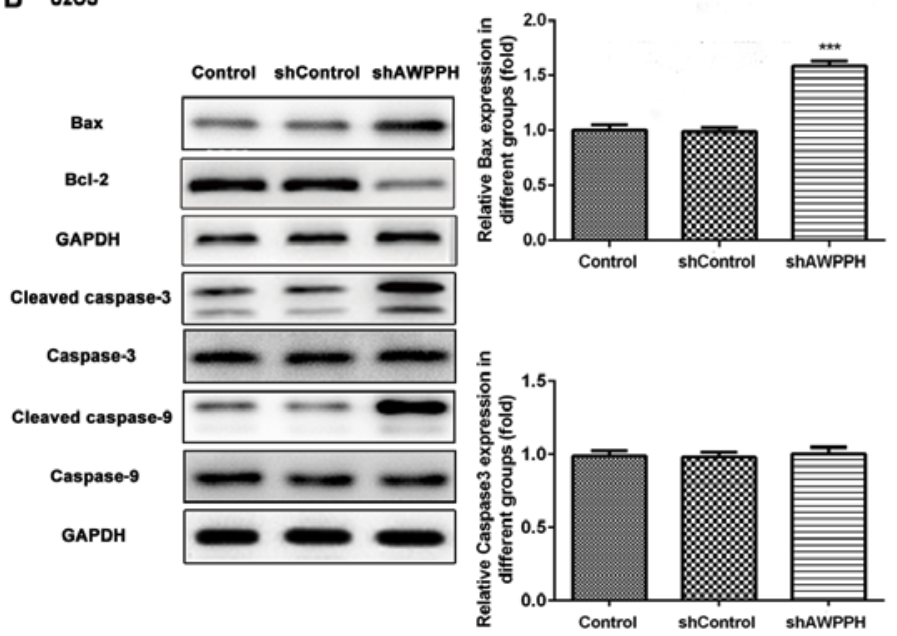

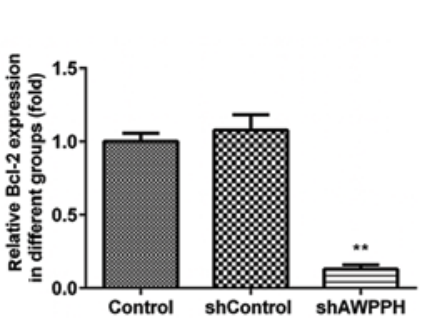
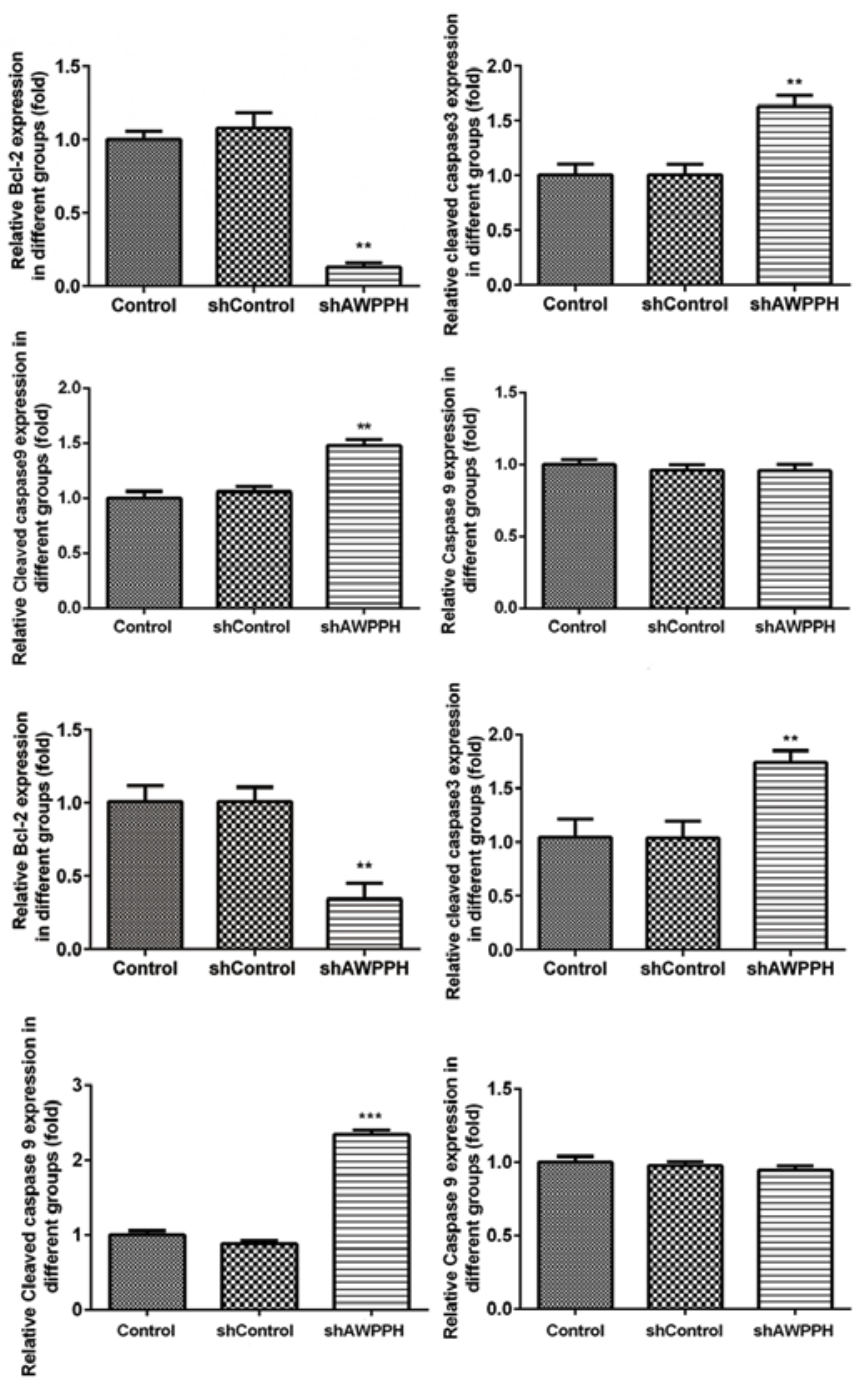

Figure 3. AWPPH downregulation promotes OS cell apoptosis. Protein expressions of Bax, Bcl-2, cleaved caspase-3, caspase-3, cleaved caspase-9 and caspase-9 in (A) MG-63 and (B) U2OS cell lines was determined by western blotting. Data are expressed as the mean \pm standard error of the mean of three independent experiments in triplicate. ${ }^{* *} \mathrm{P}<0.01$ and ${ }^{* * * *} \mathrm{P}<0.001$ compared with the control group. Sh, short hairpin.

\section{Discussion}

OS is the most frequent type of primary bone cancer, with an incidence of $0.2-3 / 100,000$ per year $(32,33)$. An increasing number of studies have suggested that the aberrant expression of IncRNAs is a potential driver event of tumorigenesis and cancer progression $(18,34,35)$. In the present study, the AWPPH expression level was significantly increased in OS tissues and cells compared with that in control groups. Furthermore, AWPPH depletion decreased OS cell proliferation, migration and invasion, promoted OS cell apoptosis and inhibited the PI3K/AKT pathway. These results demonstrated that AWPPH may be considered as a potential prognostic biomarker for OS.

A recent study reported that AWPPH is highly expressed in hepatocellular carcinoma (HCC) tissues, that it promotes HCC cell proliferation and migration in vitro, and that it promotes tumor growth and metastasis in vivo through YBX1 (29). In addition, AWPPH is highly expressed in bladder cancer (BC) and promotes cell proliferation, autophagy and migration, and inhibits cell apoptosis in BC by inhibiting SMAD family member 4 via enhancer of zeste 2 polycomb repressive complex 2 subunit (27). A previous study reported that increased expression of AWPPH is correlated with incomplete encapsulation, microvascular invasion, and advanced Tumor-Node-Metastasis stage and Barcelona clinic liver cancer stage in HCC (29). Additionally, survival analysis and Cox proportional hazards regression analysis revealed not only a correlation between AWPPH and poor recurrence-free survival and overall survival, but the fact that it is an independent prognostic factor of these measurements too (29). However, to the best of our knowledge, there are currently no reagents that target AWPPH and no studies or clinical tests on AWPHH expression in patients with OS, and the expression and role of AWPPH in OS therefore remain unknown. The present study demonstrated that AWPPH expression level was higher in OS cells compared with that in the osteoblast hFOB1.19 cell line. These results were consistent with those observed for AWPPH expression in certain subtypes of HCC and BC $(19,22)$. In the present study, the role of AWPPH in OS carcinogenesis and the one of the potential mechanisms underlying AWPPH function were elucidated via AWPPH-knockdown. MTT assay confirmed 

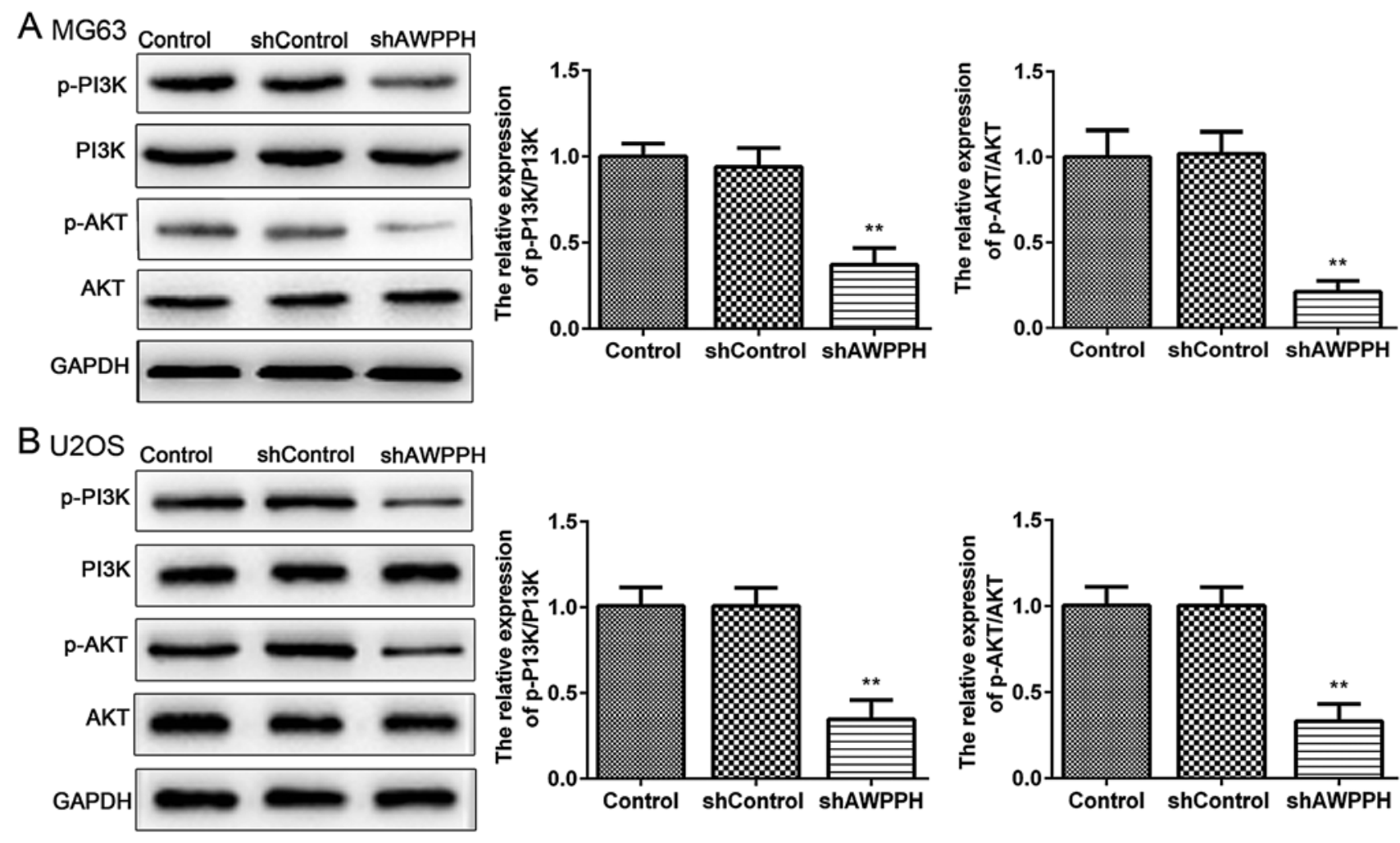

Figure 4. AWPPH downregulation inhibits the PI3K/AKT pathway. Protein expression of p-PI3K, PI3K, p-AKT and AKT in (A) MG-63 and (B) U2OS cells was determined by western blotting. Data are expressed as the mean \pm standard error of the mean of three independent experiments in triplicate. ${ }^{* *} \mathrm{P}<0.01$ compared with the control group. Sh, short hairpin.

that AWPPH-knockdown decreased OS cell proliferation. In addition, the results from the wound-healing and Transwell assays demonstrated that AWPPH depletion suppressed OS cell migration and invasion. Furthermore, western blotting analysis indicated that AWPPH-knockdown induced cell apoptosis by regulating Bcl-2, Bax, cleaved-caspase-3 and cleaved-caspase- 9 protein expressions. These results indicated that AWPPH may have an oncogenic role in OS. Further investigation using a larger clinical sample size is required to validate the expression of AWPPH in OS and to determine its potential prognostic value.

Disease recurrence and metastasis occurrence frequently result in the poor outcome of patients with OS. Numerous studies have reported that the functional roles of lncRNAs in cancer involve the carcinogenic or metastatic signaling pathways $(34,35)$. Investigating the association between signaling pathways and lncRNAs is therefore critical in order to develop novel strategies for the early diagnosis and treatment of OS. A thorough investigation has been performed of the role of the PI3K/AKT signaling pathway in cancer pathogenesis, and numerous drugs targeting this pathway are currently being developed (36). PI3K can change the protein structure of AKT and activate it, when binding to growth factor receptors, including EGFR, RAS and PTEN. PI3K can activate or inhibit a series of downstream effectors, regulating therefore cell proliferation, differentiation, apoptosis and migration. The activation of Akt by PI3k leads to the phosphorylation of apoptosis-related proteins, including Bax (37), Bad (38) and caspase-9 (39), inhibiting therefore their function of apoptosis promoters. Furthermore, the structures of growth factor receptors are all altered at some level in most solid tumors, including colorectal cancer (36), epithelial ovarian cancer (40) and cervical cancer (41). The PI3K/AKT signaling cascade and downstream effectors are therefore considered as attractive pharmacological targets $(42,43)$. In addition, it has been reported that the downregulation of DEP domain-containing mTOR-interacting protein inhibits the proliferation, migration and survival of OS cells through the PI3K/Akt/mTOR pathway (44). A recent study reported that AWPPH activates the PI3K/AKT pathway in HCC cells (29). In the present study, AWPPH downregulation significantly decreased p-PI3K and p-AKT expression levels, which indicated that the PI3K/AKT pathway may participate in the oncogenic function of AWPPH.

In conclusion, the present study demonstrated that AWPPH was highly expressed in OS cells, and that AWPPH-knockdown suppressed OS cell proliferation, migration and invasion, and promoted OS cell apoptosis, which may be mediated by PI3K/AKT pathway activation. These data suggested that AWPPH may be considered as a prognostic biomarker and a potential therapeutic target in OS.

\section{Acknowledgements}

Not applicable.

\section{Funding}

This research was supported by the National Natural Science Foundation of China (grants nos. 81272942, 81702666 and 81502328). 


\section{Availability of data and materials}

The analyzed data sets generated during the present study are available from the corresponding author on reasonable request.

\section{Authors' contributions}

WD and DW wrote the manuscript, and collected and interpreted the data. FJ and HZ designed the study and revised the manuscript. All authors read and approved the final manuscript.

\section{Ethics approval and consent to participate}

The study protocol was approved by the Ethics Committee of Changhai Hospital. Written informed consent was obtained from all patients.

\section{Patients consent for publication}

Not applicable.

\section{Competing interests}

The authors declare that they have no competing interests.

\section{References}

1. Rothermundt C, Seddon BM, Dileo P, Strauss SJ, Coleman J, Briggs TW, Haile SR and Whelan JS: Follow-up practices for high-grade extremity Osteosarcoma. BMC Cancer 16: 301, 2016.

2. Kager L, Zoubek A, Pötschger U, Kastner U, Flege S, Kempf-Bielack B, Branscheid D, Kotz R, Salzer-Kuntschik M, Winkelmann W, et al: Primary metastatic osteosarcoma: Presentation and outcome of patients treated on neoadjuvant cooperative osteosarcoma study group protocols. J Clin Oncol 21: 2011-2018, 2003

3. Anderson ME: Update on survival in osteosarcoma. Orthop Clin North Am 47: 283-292, 2016.

4. Senerchia AA, Macedo CR, Ferman S, Scopinaro M, Cacciavillano W, Boldrini E, Lins de Moraes VL, Rey G, de Oliveira CT, Castillo L, et al: Results of a randomized, prospective clinical trial evaluating metronomic chemotherapy in nonmetastatic patients with high-grade, operable osteosarcomas of the extremities: A report from the Latin American Group of Osteosarcoma Treatment. Cancer 123: 1003-1010, 2017.

5. Chung SW, Han I, Oh JH, Shin SH, Cho HS and Kim HS: Prognostic effect of erroneous surgical procedures in patients with osteosarcoma: Evaluation using propensity score matching. J Bone Joint Surg Am 96: e60, 2014

6. Cheng C, Chen ZQ and Shi XT: MicroRNA-320 inhibits osteosarcoma cells proliferation by directly targeting fatty acid synthase. Tumour Biol 35: 4177-4183, 2014.

7. Li E, Zhang J, Yuan T and Ma B: MiR-145 inhibits osteosarcoma cells proliferation and invasion by targeting ROCK1. Tumour Biol 35: 7645-7650, 2014

8. Rinn JL and Chang HY: Genome regulation by long noncoding RNAs. Annu Rev Biochem 81: 145-166, 2012.

9. Ponjavic J, Ponting CP and Lunter G: Functionality or transcriptional noise? Evidence for selection within long noncoding RNAs. Genome Res 17: 556-565, 2007.

10. ENCODEProject Consortium; Birney E,Stamatoyannopoulos JA, Dutta A, Guigó R, Gingeras TR, Margulies EH, Weng Z, Snyder M, Dermitzakis ET, et al: Identification and analysis of functional elements in $1 \%$ of the human genome by the ENCODE pilot project. Nature 447: 799-816, 2007.

11. Hirano T, Yoshikawa R, Harada H, Harada Y, Ishida A and Yamazaki T: Long noncoding RNA, CCDC26, controls myeloid leukemia cell growth through regulation of KIT expression. Mol Cancer 14: 90, 2015
12. Chen F,MoJ and Zhang L: Long noncoding RNA BCAR4 promotes osteosarcoma progression through activating GLI2-dependent gene transcription. Tumour Biol 37: 13403-13412, 2016.

13. Raveh E, Matouk IJ, Gilon M and Hochberg A: The H19 Long non-coding RNA in cancer initiation, progression and metastasis-a proposed unifying theory. Mol Cancer 14: 184, 2015.

14. Modali SD, Parekh VI, Kebebew E and Agarwal SK: Epigenetic regulation of the lncRNA MEG3 and its target c-MET in pancreatic neuroendocrine tumors. Mol Endocrinol 29: 224-237, 2015.

15. Wu XS, Wang F, Li HF, Hu YP, Jiang L, Zhang F, Li ML, Wang XA, Jin YP, Zhang YJ, et al: LncRNA-PAGBC acts as a microRNA sponge and promotes gallbladder tumorigenesis. EMBO Rep 18: 1837-1853, 2017.

16. Xiao J, Lv Y, Jin F, Liu Y, Ma Y, Xiong Y, Liu L, Zhang S, Sun Y, Tipoe GL, et al: LncRNA HANR promotes tumorigenesis and increase of chemoresistance in hepatocellular carcinoma. Cell Physiol Biochem 43: 1926-1938, 2017.

17. Hu X, Feng Y, Zhang D, Zhao SD, Hu Z, Greshock J, Zhang Y, Yang L, Zhong X, Wang LP, et al: A functional genomic approach identifies FAL1 as an oncogenic long noncoding RNA that associates with BMI1 and represses p21 expression in cancer. Cancer Cell 26: 344-357, 2014.

18. Schmitt AM and Chang HY: Long noncoding RNAs in cancer pathways. Cancer Cell 29: 452-463, 2016.

19. Peng W, Si S, Zhang Q, Li C, Zhao F, Wang F, Yu J and Ma R: Long non-coding RNA MEG3 functions as a competing endogenous RNA to regulate gastric cancer progression. J Exp Clin Cancer Res 34: 79, 2015.

20. Sun L, Yang C, Xu J, Feng Y, Wang L and Cui T: Long noncoding RNA EWSAT1 promotes osteosarcoma cell growth and metastasis through suppression of MEG3 expression. DNA Cell Biol 35: 812-818, 2016.

21. Li Z, Yu X and Shen J: Long non-coding RNAs: Emerging players in osteosarcoma. Tumour Biol 37: 2811-2816, 2016.

22. Cui X, Jing X, Long C, Tian J and Zhu J: Long noncoding RNA MEG3, a potential novel biomarker to predict the clinical outcome of cancer patients: A meta-analysis. Oncotarget 8: 19049-19056, 2017.

23. Ying L, Huang Y, Chen H, Wang Y, Xia L, Chen Y, Liu Y and Qiu F: Downregulated MEG3 activates autophagy and increases cell proliferation in bladder cancer. Mol Biosyst 9: 407-411, 2013.

24. Qin R, Chen Z, Ding Y, Hao J, Hu J and Guo F: Long noncoding RNA MEG3 inhibits the proliferation of cervical carcinoma cells through the induction of cell cycle arrest and apoptosis. Neoplasma 60: 486-492, 2013.

25. Chang L, Wang G, Jia T, Zhang L, Li Y, Han Y, Zhang K, Lin G, Zhang R, Li J and Wang L: Armored long non-coding RNA MEG3 targeting EGFR based on recombinant MS2 bacteriophage virus-like particles against hepatocellular carcinoma. Oncotarget 7: 23988-24004, 2016.

26. Cao X, Zhuang S, Hu Y, Xi L, Deng L, Sheng H and Shen W: Associations between polymorphisms of long noncoding RNA MEG3 and risk of colorectal cancer in Chinese. Oncotarget 7: 19054-19059, 2016.

27. Zhu F, Zhang X, Yu Q, Han G, Diao F, Wu C and Zhang Y: LncRNA AWPPH inhibits SMAD4 via EZH2 to regulate bladder cancer progression. J Cell Biochem 119: 4496-4505, 2018.

28. Yu G, Wang W, Deng J and Dong S: LncRNA AWPPH promotes the proliferation, migration and invasion of ovarian carcinoma cells via activation of the Wnt/ $\beta$-catenin signaling pathway. Mol Med Rep 19: 3615-3621, 2019.

29. Zhao X, Liu Y and Yu S: Long noncoding RNA AWPPH promotes hepatocellular carcinoma progression through YBX1 and serves as a prognostic biomarker. Biochim Biophys Acta Mol Basis Dis 1863: 1805-1816, 2017.

30. Guo D, Li Q, Lv Q, Wei Q, Cao S and Gu J: MiR-27a targets sFRP1 in hFOB cells to regulate proliferation, apoptosis and differentiation. PLoS One 9: e91354, 2014.

31. Livak KJ and Schmittgen TD: Analysis of relative gene expression data using real-time quantitative PCR and the 2(-Delta Delta C(T)) method. Methods 25: 402-408, 2001.

32. Bielack S, Carrle D and Casali PG; ESMO Guidelines Working Group: Osteosarcoma: ESMO clinical recommendations for diagnosis, treatment and follow-up. Ann Oncol 20 (Suppl 4): S137-S139, 2009.

33. Zhang J, Lan Q and Lin J: Identification of key gene modules for human osteosarcoma by co-expression analysis. World J Surg Oncol 16: 89, 2018. 
34. Bassett AR, Akhtar A, Barlow DP, Bird AP, Brockdorff N, Duboule D, Ephrussi A, Ferguson-Smith AC, Gingeras TR, Haerty W, et al: Considerations when investigating lncRNA function in vivo. Elife 3: e03058, 2014.

35. Gupta RA, Shah N, Wang KC, Kim J, Horlings HM, Wong DJ, Tsai MC, Hung T, Argani P, Rinn JL, et al: Long non-coding RNA HOTAIR reprograms chromatin state to promote cancer metastasis. Nature 464: 1071-1076, 2010.

36. Danielsen SA, Eide PW, Nesbakken A, Guren T, Leithe E and Lothe RA: Portrait of the PI3K/AKT pathway in colorectal cancer. Biochim Biophys Acta 1855: 104-121, 2015.

37. Gardai SJ, Hildeman DA, Frankel SK, Whitlock BB, Frasch SC Borregaard N, Marrack P, Bratton DL and Henson PM: Phosphorylation of Bax Ser184 by Akt regulates its activity and apoptosis in neutrophils. J Biol Chem 279: 21085-21095, 2004

38. Quan JH, Cha GH, Zhou W, Chu JQ, Nishikawa Y and Lee YH: Involvement of PI 3 kinase/Akt-dependent Bad phosphorylation in Toxoplasma gondii-mediated inhibition of host cell apoptosis. Exp Parasitol 133: 462-471, 2013.

39. Cardone MH, Roy N, Stennicke HR, Salvesen GS, Franke TF Stanbridge E, Frisch S and Reed JC: Regulation of cell death protease caspase-9 by phosphorylation. Science 282: 1318-1321, 1998.
40. Li C, Yu S, Wu S, Ni Y and Pan Z: MicroRNA-936 targets FGF2 to inhibit epithelial ovarian cancer aggressiveness by deactivating the PI3K/Akt pathway. Onco Targets Ther 12: 5311-5322, 2019.

41. Lee MS, Jeong MH, Lee HW, Han HJ, Ko A, Hewitt SM, Kim JH, Chun KH, Chung JY, Lee C, et al: PI3K/AKT activation induces PTEN ubiquitination and destabilization accelerating tumourigenesis. Nat Commun 6: 7769, 2015.

42. Porta C, Paglino $\mathrm{C}$ and Mosca A: Targeting PI3K/Akt/mTOR signaling in cancer. Front Oncol 4: 64, 2014.

43. Hennessy BT, Smith DL, Ram PT, Lu Y and Mills GB: Exploiting the PI3K/AKT pathway for cancer drug discovery. Nat Rev Drug Discov 4: 988-1004, 2005.

44. Hu B, Lv X, Gao F, Chen S, Wang S, Qing X, Liu J, Wang B and Shao Z: Downregulation of DEPTOR inhibits the proliferation, migration, and survival of osteosarcoma through PI3K/Akt/mTOR pathway. Onco Targets Ther 10: 4379-4391, 2017.

This work is licensed under a Creative Commons Attribution-NonCommercial-NoDerivatives 4.0 International (CC BY-NC-ND 4.0) License. 